\title{
The effectiveness of various models of primary care-based follow-up after stroke: a systematic review
}

\author{
Rhoda Allison ${ }^{1}$, Laura Shelling ${ }^{1}$, Rachel Dennett ${ }^{1}$, Tim Ayers ${ }^{1}$, Philip H. Evans ${ }^{2}$ and John L. Campbell ${ }^{2}$ \\ ${ }^{1}$ Stroke Unit, NHS Devon, Newton Abbot Hospital, Newton Abbot, Devon, UK \\ ${ }^{2}$ Peninsula Medical School (Primary Care), St Luke's Campus, Exeter, UK
}

\begin{abstract}
Aim: To systematically review studies reporting the effectiveness of various models of follow-up in primary care on a range of outcomes (physical, psychological, social functioning, or quality of life) for survivors of stroke and their caregivers. Background: Stroke is a major cause of disability globally. Current UK policy calls for a primary carebased review of healthcare and social-care needs at six weeks and six months after hospital discharge and then annually. Methods: Trials meeting the pre-defined inclusion criteria were identified by the systematic searching of electronic databases. Data were extracted by two independent researchers. Studies were rated using the McMaster University Quality Assessment Tool. Findings: Nine randomised controlled trials that met the inclusion criteria were identified. These studies included interventions using stroke support workers, care coordinators or case managers. The methodological quality of the studies was variable, and models of care demonstrated inconsistent working relationships with general practitioners. Patients and caregivers receiving formal primary care-based follow-up did not show any gains in physical function, mood, or quality of life when compared with those who did not. Patients and caregivers receiving follow-up were generally more satisfied with some aspects of communication, and had a greater knowledge of stroke. Conclusions: The limited quality of these studies and the lack of a sound theoretical basis for the development of interventions together highlight the urgent need for high-quality research studies in this area.
\end{abstract}

Key words: primary care follow-up; stroke

Received 5 November 2010; accepted 6 January 2011; first published online 11 March 2011

\section{Introduction}

The term stroke refers to a clinical syndrome, of presumed vascular origin, typified by rapidly developing signs of focal or global disturbance of cerebral function, lasting more than $24 \mathrm{~h}$ (World Health Organization, 1978). Stroke is the second most common cause of death in adults worldwide (Lopez and Mathers, 2006) and, with heart disease, is predicted to be the biggest global cause

Correspondence to: Rhoda Allison, NHS Devon, Stroke Unit, Newton Abbot Hospital, Newton Abbot, Devon, TQ12 2SL, UK. Email: Rhoda.allison@nhs.net

(C) Cambridge University Press 2011 of loss of disability-adjusted life years by 2025 (Murray and Lopez, 1997).

Two-thirds of patients will survive their first stroke but many are left with long-term disability (Hare et al., 2006), and will have ongoing needs for rehabilitation, and healthcare and social-care services. Our earlier study described the information needs of patients and caregivers after stroke (Allison et al., 2008). A number of other studies have attempted to establish the longerterm needs of patients and caregivers. Murray et al. (2003) identified that patients reported longterm difficulties in a number of areas including the physical, social, and emotional consequences 
of stroke. Hare et al. (2006) identified that patients and caregivers indicated the importance of using primary care as the first point of contact. The National Stroke Strategy in the United Kingdom (Department of Health, 2007) recommends that people and their caregivers should have access to a review from primary care providers of their healthcare and social-care status and secondary prevention needs at six weeks and six months after discharge, and then annually.

Who should undertake these reviews and within what model of care is uncertain as there is little guidance on the feasibility or effectiveness of different models of stroke follow-up in primary care. Mitchell et al. (2008) reported a systematic review of care planning involving primary care in the management of people with stroke but the majority of studies included involved coordinating the process of hospital discharge, rather than longer-term management of such people. Given this present focus of evidence on hospital-based processes, we undertook this review to investigate the evidence for the effectiveness of different models of primary care-based follow-up after stroke.

\section{Methods}

We conducted a systematic review of published research articles of interventions in primary care follow-up after stroke. We defined these as interventions involving both a healthcare and social-care element, which would be suitable to meet the requirements of the post-discharge and annual review of the stroke strategy. We interpreted this as interventions that included a review of medications and an assessment of longer-term disability and caregiver needs, as well as the provision of information and signposting to other services. We did not include studies that considered secondary prevention in isolation or that evaluated ongoing community-based rehabilitation. The review excluded studies in which followup interventions were provided by secondary care alone, but included interventions involving reaching out into primary care. The review primarily focused on how and by whom the models of follow-up care were coordinated. Articles were included if they were written in English, had targeted a population of people over the age of 18 years in primary care with a diagnosis of stroke, and where any of the following outcomes were evaluated: patient satisfaction, patient health outcome, levels of depression, patient behaviour, levels of function, quality of life, caregiver burden scales, and readmissions to hospital.

\section{Search strategy}

Multiple search strategies including electronic online database searches and hand searching of individual journals were used. The following electronic databases were searched: MEDLINE (1950-May 2008), EMBASE (1980-May 2008), CINAHL (1982-May 2008), AMED (1985-May 2008), and the Cochrane Library (1980-May 2008). The following key words were used in combinations: stroke, cerebrovascular, long-term care, chronic disease, primary health care, family practice, and community health services. Relevant papers were also identified by citation tracking, using reference lists from journals.

One investigator (RA) conducted the search. All titles or abstracts retrieved were then screened by at least two of the other investigators (RA, TA, LS, or RD) to decide whether the study was suitable for inclusion. Disagreements about eligibility were resolved by consensus or adjudication by a third investigator.

\section{Data extraction and analysis}

Key data were extracted from the identified papers using a structured form, which included the following components: general study information (title, author, and country of study), details of the intervention, study characteristics (population data, intervention, comparator, and outcomes), and findings including length of follow-up. The theoretical basis of the intervention was also extracted (if reported).

All relevant studies were independently rated by at least two of the investigators (RA, TA, LS, or RD) using the Quality Assessment Tool for quantitative studies developed by the Effective Public Health Practice Project at McMaster's University in Canada (Effective Public Health Practice Project, 2008). This tool rates a number of components for risk of bias including sample selection, study design, identification of confounding factors, blinding of assessors, reliability and validity of data collection methods, recording of withdrawals, and intervention integrity and 
analysis. The tool produces an overall rating of strong, moderate, or weak. It has been shown to have good content and construct validity, in addition to good reliability, and has been used in at least 20 systematic reviews (Thomas et al., 2004). In this review, $\kappa$-statistics were used to analyse inter-observer reliability of the overall quality rating. Any discrepancy in data extraction or quality rating was resolved through discussion.

\section{Results}

Over 20000 references were initially identified, although the majority of these did not evaluate models of care. A total of 128 abstracts were retrieved, but 119 were excluded because they focused only on secondary prevention of stroke or on ongoing community-based rehabilitation. In total, nine studies were suitable for quality assessment. All of the studies referred to were randomised controlled trials. The articles by Claiborne (2006a; 2006b) and Mant et al. (2000; 2005) presented data from the same study, but because different outcome measures were reported in the former and different time scales in the latter, they were included separately in this systematic review.

\section{Interventions}

The studies that were of sufficient quality for inclusion evaluated interventions provided by stroke support workers, care coordinators, case managers, or a care management model linked with systems of recall and clinical guidelines in primary care. All the studies identified patients before hospital discharge but did not report how long this was after the stroke. They all evaluated interventions that were provided for periods of three months up to nine months, with final followup usually at the end of the intervention period. Five studies were from the United Kingdom and four from North America.

In seven of the studies (Dennis et al., 1997; Mant et al., 2000; 2005; Lincoln et al., 2003; Tilling et al., 2005; Claiborne 2006a; 2006b), there did not appear to be a formal established relationship between the intervention worker and other primary care services. In the remaining two studies, there was evidence of a relationship linking the intervention with the patient's general practitioner
(GP), although in one of the studies the nature of this link was only loosely described (Mayo et al., 2008), and in the other (Allen et al., 2002), although the protocol detailed joint working, the detail of that relationship was not recorded.

This corresponds to the findings of Mitchell et al. (2008) who found that few studies looking at multidisciplinary care planning described the actual role provided by GPs.

\section{Theoretical basis}

The theoretical basis of the organisational model was difficult to establish in the majority of the reports because most studies presented only an introduction and a review of the methods. Four of the studies (Dennis et al., 1997; Mant et al., 2000; 2005; Lincoln et al., 2003) evaluated existing components of care. The study of stroke support workers conducted by Tilling et al. (2005) was preceded by two postal surveys, one of stroke support workers and one of patients, both suggesting what the intervention should include. The remaining studies used theoretical models of case management (Mayo et al., 2008), chronic disease management (Allen et al., 2002), and care coordination (Claiborne 2006a; 2006b), but did not formally examine the a priori evidence for these models.

\section{Methodological quality}

The methodological details reported in the papers were of variable quality. All of the studies described selection criteria and gave a full account of patients who withdrew from the study. Using the McMaster Tool, three studies were found to be of high quality, five were of moderate quality, and two were rated weak. The quality of studies is presented in Table 1 . The most common shortcomings related to lack of sample size calculations and inadequate assessor blinding. The inter-rater agreement for judging the quality of the studies was moderate ( $\kappa$-coefficient 0.59).

\section{Participants}

The participants in the studies are shown in Table 1. A total of 1425 patients and 267 caregivers participated in the studies included in the review. Broadly, the studies included a representative sample of people after stroke, although most studies excluded people who had previously 
lived in nursing homes, and two of the studies only included people with caregivers (Mant et al., 2000; 2005).

\section{Outcomes}

Most studies did not identify a single primary outcome measure but reported instead on a range of outcomes including physical functioning, mood, quality of life, hospital readmissions, and health service utilisation. In one of the studies (Allen et al., 2002), traditional measures were subsumed within composite measures, which meant that identifying the effect on individual outcomes was impossible. The heterogeneity of the interventions meant that it was not possible to meta-analyse the data. A summary of the findings is given in Table 1.

\section{Physical functioning}

Six of the nine studies included physical functioning as an outcome measure. The wellestablished Barthel Index was used as a measure in five of the studies. In addition, one study (Mayo et al., 2008) evaluated the impact of the intervention on gait speed and Timed up and Go test, two studies reported the use of the Rivermead Mobility Index (Mant et al., 2000; 2005), three studies examined the use of the Frenchay Activities Index (Dennis et al., 1997; Mant et al., 2000; 2005), and one used the Nottingham Extended Activities of Daily Living Scale (Lincoln et al., 2003). None of these studies showed any significant differences between the intervention and control groups in physical functioning.

\section{Mood}

Eight of the studies included an outcome measure of mood. Four studies used the Hospital Anxiety and Depression Scale (HADS; Dennis et al., 1997; Mant et al., 2000; 2005; Tilling et al., 2005), and the remainder used the Centre for Epidemiological Studies Depression Scale (Allen et al., 2002), the General Health Questionnaire (Lincoln et al., 2003), and the Geriatric Depression Scale (Claiborne, 2006b; Mayo et al., 2008). Claiborne (2006b) showed that patients receiving the care coordinator intervention were significantly less depressed than those in the control group. This study was the smallest with only 28 participants in total and was rated 'weak' with the
McMaster Tool. In all of the other studies, no difference was demonstrated between the intervention and control groups.

Quality of life

Six of the studies measured quality of life, using SF-36 (Mant et al., 2000; 2005; Mayo et al., 2008), Dartmouth Co-op charts (Mant et al., 2000; 2005), Euroquol EQ-5D (Mayo et al., 2008), Reintegration to Normal Living Index (Tilling et al., 2005), and Stroke-Adapted Sickness Impact Profile (Allen et al., 2002), respectively. One study (Claiborne, 2006b) indicated a significant improvement in the mental health component of SF-36, but this was a small study of overall weak quality. No other studies showed any significant difference on measures of quality of life.

\section{Health service utilisation}

Two of the studies examined health service utilisation. Mayo et al. (2008) showed that there were no differences in health service utilisation between groups receiving care from a stroke coordinator and those receiving standard care. Claiborne (2006a) showed that patients receiving case management from a social worker attended significantly more outpatient appointments but had less emergency attendances than those in a control group. However, the sample size was small $(n=28)$ and there was large variation in each individual's use of services.

\section{Patient behaviour}

Only one study (Claiborne, 2006b) reported the effects of the intervention on patient behaviour. Claiborne measured behaviour through an index of self-care that included concordance with medication regimes and attendance at hospital appointments. Although the study showed a significant improvement in adherence to self-care in favour of intervention, it is unclear how this was measured on the index or how the validity of the measure was established.

\section{Satisfaction}

Five studies reported patient and caregiver satisfaction with services. Four of these studies (Dennis et al., 1997; Mant et al., 2000; 2005; Tilling et al., 2005) used a formally developed satisfaction questionnaire, and the other (Lincoln et al., 2003) used a questionnaire designed by the study team. 
Table 1 Review of included studies

\begin{tabular}{|c|c|c|c|c|c|c|c|}
\hline $\begin{array}{l}\text { Authors and } \\
\text { Journal }\end{array}$ & $\begin{array}{l}\text { Theoretical } \\
\text { framework }\end{array}$ & Intervention & $\begin{array}{l}\text { Number of } \\
\text { participants }\end{array}$ & $\begin{array}{l}\text { Quality } \\
\text { rating }\end{array}$ & $\begin{array}{l}\text { Follow-up } \\
\text { point }\end{array}$ & Outcome measures & Impact on outcomes \\
\hline $\begin{array}{l}\text { Allen et al. (2002), } \\
\text { Journal of } \\
\text { Stroke and } \\
\text { Cerebrovascular } \\
\text { Disease }\end{array}$ & $\begin{array}{l}\text { Chronic care } \\
\text { model }\end{array}$ & $\begin{array}{l}\text { Care manager, } \\
\text { clinical } \\
\text { information } \\
\text { systems, self- } \\
\text { management }\end{array}$ & 93 patients & Moderate & 3 months & $\begin{array}{l}\text { Barthel, stroke } \\
\text { knowledge, CES-D, } \\
\text { readmissions, BP } \\
\text { control, SA-SIP30 }\end{array}$ & $\begin{array}{l}\text { Patients in intervention group } \\
\text { had greater stroke knowledge, } \\
\text { and less hospital readmission } \\
\text { No differences in other } \\
\text { measures }\end{array}$ \\
\hline $\begin{array}{l}\text { Claiborne (2006a), } \\
\text { Research on } \\
\text { Social Work } \\
\text { Practice }\end{array}$ & $\begin{array}{l}\text { Care } \\
\text { coordination }\end{array}$ & $\begin{array}{l}\text { Social work } \\
\text { care } \\
\text { coordination }\end{array}$ & 28 patients & Weak & 3 months & $\begin{array}{l}\text { Health service } \\
\text { utilisation }\end{array}$ & $\begin{array}{l}\text { Patients in intervention group } \\
\text { attended significantly more } \\
\text { outpatient appointments and } \\
\text { significantly less emergency } \\
\text { attendances than controls }\end{array}$ \\
\hline $\begin{array}{l}\text { Claiborne (2006b), } \\
\text { Health and } \\
\text { Social Work }\end{array}$ & $\begin{array}{l}\text { Care } \\
\text { coordination }\end{array}$ & $\begin{array}{l}\text { Social work } \\
\text { care } \\
\text { coordination }\end{array}$ & 28 patients & Weak & 3 months & $\begin{array}{l}\text { SF-36, GDS, } \\
\text { 'adherence' } \\
\text { assessment }\end{array}$ & $\begin{array}{l}\text { Patients in intervention group } \\
\text { were significantly less } \\
\text { depressed and more likely to } \\
\text { adhere to self care practice }\end{array}$ \\
\hline $\begin{array}{l}\text { Dennis et al. } \\
\text { (1997), British } \\
\text { Medical } \\
\text { Journal }\end{array}$ & $\begin{array}{l}\text { Evaluation } \\
\text { of existing } \\
\text { component } \\
\text { of care }\end{array}$ & $\begin{array}{l}\text { Stroke support } \\
\text { worker }\end{array}$ & 417 patients & Strong & 6 months & $\begin{array}{l}\text { Barthel, Oxford } \\
\text { Handicap score, } \\
\text { FAI, GHQ, HADS }\end{array}$ & $\begin{array}{l}\text { Higher satisfaction with } \\
\text { information but higher } \\
\text { incidence of depression for } \\
\text { patients in intervention group } \\
\text { Higher satisfaction with } \\
\text { information for caregivers in } \\
\text { intervention group } \\
\text { No other differences }\end{array}$ \\
\hline $\begin{array}{l}\text { Lincoln et al. } \\
\text { (2003), Stroke }\end{array}$ & $\begin{array}{l}\text { Evaluation } \\
\text { of existing } \\
\text { component }\end{array}$ & Stroke FSO & 187 patients & Moderate & 9 months & $\begin{array}{l}\text { GHQ, Not EADL, } \\
\text { Barthel, perceived } \\
\text { knowledge }\end{array}$ & $\begin{array}{l}\text { Intervention group had } \\
\text { improved levels of stroke } \\
\text { knowledge } \\
\text { No other differences }\end{array}$ \\
\hline $\begin{array}{l}\text { Mant et al. (2000), } \\
\text { The Lancet }\end{array}$ & $\begin{array}{l}\text { Evaluation } \\
\text { of existing } \\
\text { component } \\
\text { of care }\end{array}$ & Stroke FSO & $\begin{array}{l}323 \text { patients } \\
267 \text { caregivers }\end{array}$ & Strong & 6 months & $\begin{array}{l}\text { FAl, SF-36, } \\
\text { knowledge, Barthel, } \\
\text { RMI, LHS, HADs, } \\
\text { GHQ, Dartmouth } \\
\text { co-op charts }\end{array}$ & $\begin{array}{l}\text { Caregivers in intervention } \\
\text { group had greater social } \\
\text { activities and quality of life } \\
\text { There were no significant } \\
\text { differences for patients }\end{array}$ \\
\hline $\begin{array}{l}\text { Mant et al. (2005), } \\
\text { Journal of } \\
\text { Neurology, } \\
\text { Neurosurgery, } \\
\text { and Psychiatry }\end{array}$ & $\begin{array}{l}\text { Evaluation } \\
\text { of existing } \\
\text { component } \\
\text { of care }\end{array}$ & Stroke FSO & $\begin{array}{l}294 \text { patients } \\
112 \text { caregivers }\end{array}$ & Moderate & 12 months & As previous & $\begin{array}{l}\text { No significant difference for } \\
\text { patients or caregivers }\end{array}$ \\
\hline $\begin{array}{l}\text { Mayo et al. (2008), } \\
\text { Age and Ageing }\end{array}$ & $\begin{array}{l}\text { Case } \\
\text { management }\end{array}$ & $\begin{array}{l}\text { Nurse case } \\
\text { manager } \\
\text { linking with } \\
\text { personal } \\
\text { physician }\end{array}$ & 190 patients & Moderate & 6 months & $\begin{array}{l}\text { Health service } \\
\text { utilisation, physical } \\
\text { component SF-36, } \\
\text { Barthel, gait speed, } \\
\text { TUG, GDS }\end{array}$ & $\begin{array}{l}\text { Fewer specialist visits in } \\
\text { intervention group in post } \\
\text { intervention period } \\
\text { No other differences }\end{array}$ \\
\hline
\end{tabular}




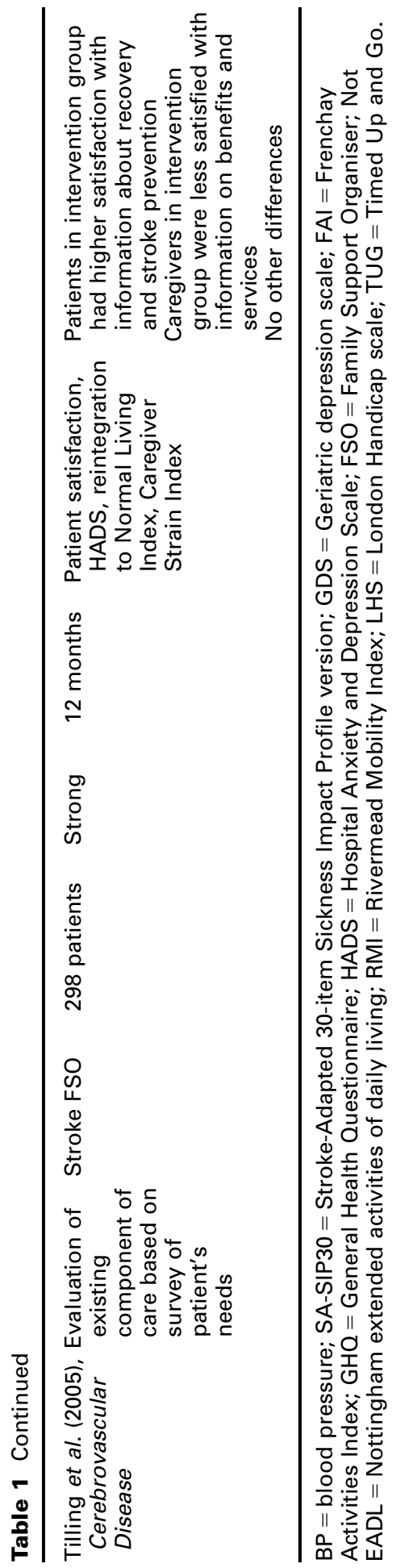

With regard to patient satisfaction, none of the studies showed a significant difference in overall satisfaction, although some of the studies identified differences in response to individual aspects of satisfaction. For example, in Dennis et al. (1997), patients in the intervention group felt someone had listened to their needs. Tilling et al. (2005) showed small non-significant effects with higher satisfaction with information about stroke prevention but lower satisfaction with community services, and Lincoln et al. (2003) found that patients in the intervention group were more satisfied with information about community services and about emotional support.

For caregivers, two studies (Mant et al., 2000; Tilling et al., 2005) showed no differences in caregiver satisfaction. Lincoln et al. (2003) showed a statistically higher level of satisfaction for caregivers in the questions concerning provision of information on emotional support and practical help, but this did not translate into a difference in overall satisfaction. Dennis et al. (1997) found that carergivers receiving follow-up were significantly more likely to feel that someone had listened and were less likely to feel neglected.

\section{Perceived knowledge}

Three of the studies examined the perceived knowledge of both patients and caregivers (Mant et al., 2000; 2005; Lincoln et al., 2003), and one looked at patients alone (Allen et al., 2002). All of these studies used questionnaires designed by each study team, usually to assess knowledge of whom to call in the event of another stroke, how to access information, and secondary prevention. None of the studies described how these questionnaires had been validated and the findings were inconsistent. Lincoln et al. (2003) showed that both patients and caregivers in the intervention group had a higher perceived knowledge of stroke, risk factors, and resources available. Allen et al. (2002) also showed a positive benefit for patients. However, Mant et al. (2000; 2005) established no differences for either patients or caregivers in respect of knowledge regarding stroke.

\section{Caregiver strain}

Five of the studies measured caregiver burden: four used the Carer Strain Index (Mant et al., 2000; 2005; Lincoln et al., 2003; Tilling et al., 2005) 
and one used the Care Giving Hassles Scale (Dennis et al., 1997). Although the trend in one study was for less strain in caregivers in the intervention group (Dennis et al., 1997), there were no significant differences observed in favour of the intervention group in any of the studies. Four of the studies also looked at care-giver mood and socialisation. Although two studies showed no impact on caregiver mood using HADS (Tilling et al., 2005) or General Health Questionnaire (Lincoln et al., 2003), Mant et al. (2000) showed that caregivers in the intervention group reported less depression on the HADS and were involved in significantly more social activities. These positive effects were continued at followup at one year.

\section{Adverse events}

Adverse events or side effects of the interventions were not reported in any of the studies.

In summary, patients and caregivers receiving formal primary care follow-up delivered using a range of models did not show any gains in physical function, mood, or quality of life. Some patients and caregivers receiving follow-up were more satisfied with some aspects of communication, and had a higher perceived knowledge of stroke, but these were not consistently shown. In two of the studies, patients receiving follow-up had fewer emergency attendances when compared with patients not receiving follow-up.

\section{Discussion}

The aim of this systematic review was to evaluate the effectiveness of models of primary care-based follow-up after stroke. The studies identified compared groups of patients and caregivers who received contact with stroke support workers, care coordinators, and case managers with those who received standard care. From the evidence reviewed, there is insufficient evidence to support or refute the value of these models of follow-up after stroke.

Most of the studies included in this review provided an inadequate description of their methods to allow a full assessment of their methodological quality. Where detailed methods were described, most studies were found to be of only moderate quality. Given the relatively small sample size of most of these trials, a lack of statistically significant differences between groups may simply reflect a lack of statistical power rather than the absence of a real effect. The heterogeneity of the interventions meant that it was not possible to metaanalyse the data.

The choice of outcomes may also have affected the ability to demonstrate an effect. First, it is unclear whether the outcomes selected would be sensitive to change. For example, models of follow-up based on general support and information transfer are unlikely to directly affect physical function, and since the models did not include a formal intervention to manage depression, such as a psychological therapy, they may be unlikely to affect mood. Only two of the studies identified primary outcome measures (Tilling et al., 2005; Mayo et al., 2008). Most of the studies measured a wide range of outcomes and it was often unclear exactly which outcome the intervention was targeting. It is also possible that the choice of outcomes was not ideal, as some may have shown ceiling effects. The Barthel Index, for example, focuses on basic physical function, and in three of the studies, most participants had achieved the maximum scores at the time of the final measure.

The majority of studies did not report a sound theoretical basis for the development of the intervention given. It is essential that a 'complex intervention', such as a model of healthcare and social-care follow-up, has a theoretical basis (Medical Research Council, 2008). Theoretical models of chronic disease management (Wagner, 1998) have been used to improve approaches to care in other conditions, such as diabetes (Wagner et al., 2001) and chronic pulmonary disease (Adams et al., 2007), and consideration should be given to the value of these models for stroke.

Finally, although the interventions provided took place in the community, there appeared to be little attention paid to the extent and quality of communication between intervention staff and the patient's GP. There is significant evidence to show how poor communication between primary care and secondary care clinicians, or other community services may have a negative impact on patient care (White and Marriot, 2004; Farquhar et al., 2005). We would, therefore, suggest that future studies of follow-up give consideration to the mechanisms of communication and interface with primary care staff. 
The National Stroke Strategy (Department of Health, 2007) recommends that stroke survivors and their caregivers are provided with a healthcare and social-care review by primary care professionals at key points following their discharge from hospital, and that patients and caregivers have identified the importance of primary care as a first point of contact (Hare et al., 2006). Currently, there is very little evidence on which to base models for providing these reviews. Further research is underway to evaluate a comprehensive assessment approach to post-acute stroke care (Murray et al., 2006), but attention may still need to be given on how assessment roles link with GPs. Further research is needed to inform future practice, and examples of chronic disease management, such as those increasingly used in the United States, may be useful in developing models of follow-up after stroke.

\section{Conclusions}

Overall, the findings do not support the use of stroke support workers, care coordinators, or case managers working in the ways described in these studies to deliver the primary care-based healthcare and social-care review after stroke. The lack of a theoretical model on which to base the worker's intervention, and the lack of a defined relationship or route of communication with the stroke survivor's GP may be potential reasons for the lack of positive effect.

The lack of a sound theoretical basis for the development of primary care-based follow-up after stroke highlights the need for urgent work to develop this. The Complex Interventions Framework (Medical Research Council, 2008) provides some guidance on how this could be developed. The limited quality of the studies considered in this review highlights the need for high-quality trials of primary care-based interventions aimed at following up patients who have sustained a stroke.

\section{References}

Adams, S.G., Smith, P.K., Allan, P.F., Anzueto, A., Pugh, J.A. and Cornell, J.E. 2007: Systematic review of the chronic care model in chronic obstructive pulmonary disease prevention and management. Archives of Internal Medicine 167, 551-61.
Allen, K.R., Hazelett, S., Jarjoura, D., Wickstrom, G.C., Hua, K., Weinhardt, J. and Wright, K. 2002: Effectiveness of a postdischarge care management model for stroke and transient ischemic attack: a randomized trial. Journal of Stroke and Cerebrovascular Diseases 11, 88-98.

Allison, R., Evans, P.H., Kilbride, C. and Campbell, J.L. 2008: Secondary prevention of stroke: using the experiences of patients and carers to inform the development of an educational resource. Family Practice 25, 355-61.

Claiborne, N. 2006a: Efficiency of a care coordination model: a randomized study with stroke patients. Research on Social Work Practice 16, 57-66.

Claiborne, N. 2006b: Effectiveness of a care coordination model for stroke survivors: a randomized study. Health and Social Work 31, 87-96.

Dennis, M., O'Rourke, S., Slattery, J., Staniforth, T. and Warlow, C. 1997: Evaluation of a stroke family care worker: results of a randomised controlled trial. British Medical Journal 314, 1071.

Department of Health. 2007: National stroke strategy. London: Department of Health.

Effective Public Health Practice Project. 2008: Quality assessment tool for quantitative studies. Retrieved 10 March 2008 from http://www.ephpp.ca/Tools.html

Farquhar, M.C., Barclay, S.I.G., Earl, H., Grande, G.F., Emery, J. and Crawford, R.A.F. 2005: Barriers to effective communication across the primary/secondary interface: examples from the ovarian cancer patient journey (a qualitative study). European Journal of Cancer Care 14, 359-66.

Hare, R., Rogers, H., Lester, H., McManus, R.J. and Mant, J. 2006: What do stroke patients and their carers want from community services? Family Practice 23, 131-36.

Lincoln, N., Francis, V.M., Lilley, S.A., Sharma, J.C. and Summerfield, M. 2003: Evaluation of a stroke family support organiser: a randomized controlled trial. Stroke 34, 116-21.

Lopez, A.D. and Mathers, C.D. 2006: Measuring the global burden of disease and epidemiological transitions: 2002-2030. Annals of Tropical Medicine and Parisitology 100, 481-99.

Mant, J., Carter, J., Wade, D.T. and Winner, S. 2000: Family support for stroke: a randomised controlled trial. The Lancet 356, 808-13.

Mant, J., Winner, S., Roche, J. and Wade, D.T. 2005: Family support for stroke: one year follow up of a randomised controlled trial. Journal of Neurology, Neurosurgery, and Psychiatry 76, 1006-08.

Mayo, N.E., Nadeau, L., Ahmed, S., White, C., Grad, R., Huang, A., Yaffe, M.J. and Wood-Dauphinee, S. 2008: Bridging the gap: the effectiveness of teaming a stroke coordinator with patient's personal physician on the outcome of stroke. Age and Ageing 37, 32-38.

Medical Research Council. 2008: Developing and evaluating complex interventions: new guidance. London: Medical Research Council. 
Mitchell, G.K., Brown, R.M., Erikssen, L. and Tieman, J.J. 2008: Multidisciplinary care planning in the primary care management of completed stroke: a systematic review. BMC Family Practice 9, 44.

Murray, C.J. and Lopez, A.D. 1997: Alternative projections of mortality and disability by cause 1990-2020: Global Burden of Disease Study. Lancet 349, 1498-504.

Murray, J., Ashworth, R., Forster, A. and Young, J. 2003: Developing a primary care-based stroke service: a review of the qualitative literature. British Journal of General Practice 53, 137-42.

Murray, J., Young, J., Forster, A., Herbert, G. and Ashworth, R. 2006: Feasibility study of a primary care-based model for stroke aftercare. British Journal General Practice 1, 775-80.

Thomas, B.H., Ciliska, D., Dobbins, M. and Micucci, S. 2004: A process for systematically reviewing the literature: providing the research evidence for public health nursing interventions. Worldviews on Evidence-Based Nursing 1, 176-84.

Tilling, K., Coshall, C., McKevitt, C., Daneski, K. and Wolfe, C. 2005: A family support organiser for stroke patients and their carers: a randomised controlled trial. Cerebrovascular Disease 20, 85-91.

Wagner, E.H. 1998: Chronic disease management: what will it take to improve care for chronic illness? Effective Clinical Practice 1, 2-4.

Wagner, E.H., Grothaus, L.C., Sandhu, N., Galvin, M.S., McGregor, M., Artz, K. and Coleman, E.A. 2001: Chronic care clinics for diabetes in primary care. Diabetes Care 244, 695-700.

White, T. and Marriot, S. 2004: Using evidence-based dissemination and implementation strategies to improve routine communication between general practitioners and community mental health teams. Psychiatric Bulletin 28, 8-11.

World Health Organization. 1978: Cerebrovascular disorders: $a$ clinical and research classification. Geneva: World Health Organization.

\section{Appendix 1: Search Strategy}

\author{
MEDLINE, CINAHL, EMBASE, AMED, BNI
}

1. Stroke

2. Cerebrovascular

3. CVA

4. CVE

5. Vascular accident

6. Long-term care

7. Chronic disease

8. Primary health care

9. Family practice

10. Community health services

11. Follow-up

12. $1,2,3,4$, or 5

13. $6,7,8,9,10$, or 11

14. 12 and 13

Cochrane Stroke Group Trials Register, Cochrane Central Register of Controlled Trials (CENTRAL), Cochrane Effective Practice, and Organisation of Care Group (EPOC)

1. Stroke

2. Long-term care

3. Chronic disease

4. Primary health care

5. Family practice

6. Community health services

7. Follow-up

8. 2 or 3 or 4 or 5 or 6 or 7

9. 1 and 8

Department of Health data, Kings Fund 